programmes. The Bush administration has also proactively pursued research evaluation through the all-powerful White House Office of Management and Budget (OMB), which sets the president's annual budget proposal. A lot of evaluation is now taking place. And to its credit, the OMB seems to have focused much of its attention on programmes that are not properly peer reviewed.

But in the end, what is the evidence that anyone in the government is listening? Where are the examples of programmes that the administration doesn't like being revived because they perform well - or ones that it intuitively favours being cut back?

Evaluation that doesn't work is, according to a discussion at the annual meeting of the American Association for the Advancement of Science (AAAS) last month, worse than none at all. It costs a substantial amount of money - anything from $0.25 \%$ to $2 \%$ of the cost of the programme under scrutiny - and it exhausts and sometimes demoralizes the researchers obliged to participate. Some argue that this process is of inherent value in lending direction to projects and programmes, but that is a minority view.

Even so, demands for accountability will not go away. The systems in place, flawed as they may be, are unlikely to be dismantled. In Japan, hard-done-by researchers are in rebellious mood (see Nature 438, $1051-1052 ; 2005)$. And in the United States, the process contains little of the transparency Americans expect of their government.

The OMB is almost as secretive as it is powerful - but researchers need to be convinced that all of its evaluation is leading somewhere. Congress should therefore ask the Government Accountability Office to report on the OMB evaluation process as it relates to science and technology. Such a study, from a watchdog of established integrity, might reassure research managers that they are not being sent each year on a wild goose chase.

\section{Gradual force}

\section{A delicate probe, twenty years old this week, has transformed our understanding of the nanoscale.}

V hat difference can a breakthrough in science make over two decades? A quick comparison of the respective fates of two discoveries made twenty years ago reaffirms how daft it is to try to predict research outcomes over such a timescale.

Both tales begin at IBM's Zurich research laboratory in the early 1980 s. In one corner of the lab, Gerd Binnig, Heinrich Rohrer and others were building an instrument that would come to be known as a scanning tunnelling microscope (STM). In another, Georg Bednorz and Alexander Müller were doing experiments on materials that they thought might hold promise as superconductors.

In early 1986, Bednorz and Müller got the first hints that they were on to something. An oxide of lanthanum, barium and copper seemed to retain the ability to conduct electricity without resistance at temperatures of up to $35 \mathrm{~K}\left(-238^{\circ} \mathrm{C}\right)$. This, at the time, was striking: for more than a decade, the ceiling on transition temperatures for superconductors had been stuck at less than $24 \mathrm{~K}$.

Within months of publishing their first paper (Z. Phys. B 64, $189-193 ; 1986)$, the result was successfully replicated, and interest in its ramifications exploded. The buzz over high-temperature superconductivity at the March 1987 meeting of the American Physical Society in New York was such that The New York Times dubbed the event "the Woodstock of physics".

By the time Bednorz and Müller picked up their Nobel prize in December of the same year, similar ceramic materials that could superconduct at the temperature ofliquid nitrogen, $77 \mathrm{~K}\left(-196^{\circ} \mathrm{C}\right)$, had been discovered. This, it was thought, would open the door to widespread practical use - and, briefly, industrial and government funding surged in at the speed of the magnetically levitating trains that the field was, according to countless news stories, due to produce in the fullness of time.

By contrast, few members of the public had even heard of the humble scanning tunnelling microscope, which Binnig and Rohrer first described in an internal IBM document in March 1981. It took until 1986, by which time the STM was already widelyused to study materials, for them to receive the Nobel prize.

An STM exploits a quantum phenomenon called electron tunnelling: when two conducting materials are held close together and a voltage is applied, electrons hop from one to the other, producing a current that is highly sensitive to the distance of separation. An STM scans a sharp tip over a surface, translating the current registered into a topographical map of the surface. The instrument was powerful enough to reveal the positions of atoms.

But the STM only worked for materials that conduct electricity, which many of the things that interest biologists and materials scientists don't do. This problem was addressed by a paper published twenty years ago this week, on 3 March 1986. The paper, 'Atomic force microscope' (Phys. Rev. Lett. 56, 930-933; 1986), introduced the instrument that has fuelled the current explosion of interest in nanotechnology.

The atomic force microscope traces topography by scanning a sharp tip over the surface. It measures tiny forces between the tip and the sample via the deflection of a thin cantilever to which the tip is attached. This is
"Atomic force microscopy is an immensely versatile technique." an immensely versatile technique (see page 14), and that first paper has clocked up more than 4,500 citations.

High-temperature superconductivity, on the other hand, never quite lived up to its commercial hype. The materials in question have been difficult to fabricate, their properties are more constrained than some physicists had hoped, and there is still no agreement on why they work as they do (see papers in this month's Nature Physics). The materials remain rich systems for experimental study and pose intriguing theoretical problems, but their practical use is largely confined to making superconducting quantum interference devices (SQUIDs) to measure magnetic fields, and prototype transmission lines that can carry high-density current.

In terms of their technological and economic application, it looks like the dark horse made it to the wire first. That should serve to remind managers of research agencies and industrial laboratories of the folly of trying to predict how much value any particular scientific breakthrough may hold. 